\title{
ESTUDO DAS CARACTERÍSTICAS FÍSICO-QUÍMICAS DE DIVERSOS MÉTODOS DE PREPARO DE CAFÉ DAS VARIEDADES ARÁBICA (COFFEA ARABICA L.) E ROBUSTA (COFFEA CANEPHORA).
}

\author{
Flávia Santana Santos ${ }^{1}$ e Luiz Severo da Silva Júnior ${ }^{2}$ \\ 1. Bolsista PIBIC/FAPESB, Graduanda em Engenharia de Alimentos, Universidade Estadual de Feira de Santana, e- \\ mail: santos_flavinha1996@hotmail.com \\ 2. Orientador, Departamento de Tecnologia, Universidade Estadual de Feira de Santana, e-mail: severo@uefs.br
}

PALAVRAS-CHAVE: café, análise, qualidade.

\section{INTRODUÇÃO}

O café é uma das bebidas mais aceitas e apreciadas por diversos países no mundo, por ser um produto natural, com aromas e sabores distintos. Dentre as espécies mais cultivadas, destaca-se o café arábica (Coffea arabica L.), que apresenta melhor qualidade, proporcionando uma bebida de maior valor comercial e alcançando preços superiores aos do robusta (Coffea canephora), cuja bebida, considerada neutra, é muito usada nas misturas ou blends e na indústria de café solúvel, sendo favorecida pelo preço mais reduzido e pela maior concentração de sólidos solúveis, o que representa um maior rendimento industrial (ILLY e VIANNI, 1996).

A qualidade do café torrado e moído está profundamente relacionada com a sua composição físico-química. Desta forma, este trabalho foi baseado no estudo das características físico-químicas de infusões de café obtidas pelos diversos métodos de preparação de grãos de café conilon e arábica, considerando a origem, variedade, grau de torrefação e de moagem. A matriz em estudo foi originada do estado da Bahia, onde ocorreu a preparação de diversos tipos de bebidas, pelos métodos: expresso, turco, coador de papel, cold brew (gelado), italiano, prensa francesa e Hario V60.

\section{MATERIAL E MÉTODOS OU METODOLOGIA (ou equivalente)}

Foram coletadas amostras dos grãos de diferentes lotes e data de torrefação, sendo estes, os mais recentes possíveis. Nestas amostras de grãos de café torrados do tipo conilon e arábica aplicou-se moagens adequadas para o tipo de preparo da bebida (café) que se desejava preparar, visto que, cada método de preparo exige uma moagem específica para obtenção de uma bebida de qualidade. Estas moagens foram realizadas com auxílio de um moedor elétrico profissional da marca Tramontina By Breville. Diversos métodos de preparo da bebida foram executados, como: preparação do expresso, turco, coador de papel, gelado, italiano, prensa francesa, Hario V60.

Foram realizadas análises em todas as amostras extraídas dos diferentes métodos de preparo das duas espécies de café, tais como, análise de pH, cafeína, acidez, lipídios e resíduo seco, da bebida recentemente preparada. Todas essas análises foram realizadas por métodos oficiais e devidamente validadas pelo Instituto Adolfo Lutz - Métodos Físico-Químicos para Analise de Alimentos - 4a Edição - 1985. Os grãos foram padronizados em relação a granulometria e quantidade de pó que foi utilizado para cada método de preparo da amostra, a água utilizada apresentava-se sempre com o pH neutro, temperatura de $98^{\circ} \mathrm{C}$ (quando foi necessário a utilização) e sempre com o mesmo 
volume para cada um dos métodos de preparo, o tempo de extração também foi mantido constante.

\section{RESULTADOS E/OU DISCUSSÃO (ou Análise e discussão dos resultados)}

$\mathrm{Na}$ Tabela 1 verificam-se os resultados das propriedades físico-químicas investigadas para as amostras de cafés arábica e conilon para cada método de preparo avaliados.

Tabela 1: Propriedades físico-químicas das amostras de café.

\begin{tabular}{|c|c|c|c|c|c|c|}
\hline Método & $\begin{array}{l}\text { Tipo De } \\
\text { Grão }\end{array}$ & $p H$ & $\begin{array}{l}\text { Acidez }(\% \\
v / m)\end{array}$ & $\begin{array}{l}\text { Resíduo } \\
\text { Seco }(\% \\
m / v)\end{array}$ & $\begin{array}{l}\text { Lipídeos } \\
(\% \mathrm{~g} / \mathrm{g})\end{array}$ & $\begin{array}{l}\text { Cafeína } \\
(\mathrm{mg} / 100 \mathrm{~m} \\
\text { l) }\end{array}$ \\
\hline \multirow[t]{2}{*}{ Expresso } & Arábica & $\begin{array}{ll}5,07 & \pm \\
0,006 & \end{array}$ & $\begin{array}{l}3,56 \\
0,015\end{array}$ & $\begin{array}{ll}1,44 & \pm \\
0,179 & \end{array}$ & $\begin{array}{l}0,76 \\
0,064\end{array}$ & $\begin{array}{ll}0,0041 \quad \pm \\
0,0000\end{array}$ \\
\hline & Conilon & $\begin{array}{l}5,38 \\
0,038\end{array}$ & $\begin{array}{l}3,48 \\
0,016\end{array}$ & $\begin{array}{l}1,44 \\
0,137\end{array}$ & $\begin{array}{l}1,32 \\
0,392\end{array}$ & $\begin{array}{l}0,0105 \quad \pm \\
0,00002\end{array}$ \\
\hline \multirow{2}{*}{$\begin{array}{l}\text { Café Coado } \\
\text { Em Filtro } \\
\text { Tradicional }\end{array}$} & Arábica & $\begin{array}{l}5,07 \\
0,032\end{array}$ & $\begin{array}{l}1,43 \\
0,015\end{array}$ & $\begin{array}{l}1,46 \\
0,007\end{array}$ & $\begin{array}{l}0,79 \\
0,139\end{array}$ & $\begin{array}{l}0,0035 \quad \pm \\
0,00001\end{array}$ \\
\hline & Conilon & $\begin{array}{l}5,57 \\
0,006 \\
\end{array}$ & $\begin{array}{l}1,07 \\
0,053\end{array}$ & $\begin{array}{l}1,77 \\
0,007\end{array}$ & $\begin{array}{l}0,90 \\
0,061\end{array}$ & $\begin{array}{l}0,0061 \quad \pm \\
0,00003\end{array}$ \\
\hline \multirow{2}{*}{$\begin{array}{l}\text { Café Coado } \\
\text { Com } \\
\text { Filtração } \\
\text { Hario V60 }\end{array}$} & Arábica & $\begin{array}{l}5,04 \\
0,026\end{array}$ & $\begin{array}{l}1,47 \\
0,036\end{array}$ & $\begin{array}{l}1,17 \\
0,421\end{array}$ & $\begin{array}{l}0,17 \\
0,006\end{array}$ & $\begin{array}{l}0,0029 \quad \pm \\
0,00002\end{array}$ \\
\hline & Conilon & $\begin{array}{l}5,59 \\
0,020\end{array}$ & $\begin{array}{l}0,97 \\
0,036\end{array}$ & $\begin{array}{l}1,65 \\
0,004\end{array}$ & $\begin{array}{l}0,34 \\
0,279\end{array}$ & $\begin{array}{ll}0,0051 \quad \pm \\
0,00001\end{array}$ \\
\hline \multirow[t]{2}{*}{$\begin{array}{l}\text { Café Italiano } \\
\text { (Bialeti) }\end{array}$} & Arábica & $\begin{array}{l}5,10 \\
0,032 \\
\end{array}$ & $\begin{array}{l}5,35 \\
0,010 \\
\end{array}$ & $\begin{array}{l}3,17 \\
0,038\end{array}$ & $\begin{array}{l}3,68 \\
0,006 \\
\end{array}$ & $\begin{array}{l}0,0022 \quad \pm \\
0,00005\end{array}$ \\
\hline & Conilon & $\begin{array}{l}5,60 \\
0,011\end{array}$ & $\begin{array}{l}4,01 \\
0,012\end{array}$ & $\begin{array}{l}4,90 \\
0,023\end{array}$ & $\begin{array}{l}4,93 \\
0,178\end{array}$ & $\begin{array}{l}0,0086 \quad \pm \\
0,00002\end{array}$ \\
\hline \multirow[t]{2}{*}{$\begin{array}{ll}\text { Café } & \text { Turco } \\
\text { (Ibrik) } & \end{array}$} & Arábica & $\begin{array}{l}5,28 \\
0,017\end{array}$ & $\begin{array}{l}2,20 \\
0,015\end{array}$ & $\begin{array}{l}2,50 \\
0,284\end{array}$ & $\begin{array}{l}2,91 \\
0,256\end{array}$ & $\begin{array}{l}0,0101 \quad \pm \\
0,0000\end{array}$ \\
\hline & Conilon & $\begin{array}{l}5,89 \\
0,085\end{array}$ & $\begin{array}{l}0,90 \\
0,006\end{array}$ & $\begin{array}{l}4,37 \\
0,639\end{array}$ & $\begin{array}{l}2,84 \\
0,345\end{array}$ & $\begin{array}{l}0,0149 \quad \pm \\
0,00003\end{array}$ \\
\hline \multirow[t]{2}{*}{ Café Gelado } & Arábica & $\begin{array}{l}5,31 \\
0,21\end{array}$ & $\begin{array}{l}1,50 \\
0,025\end{array}$ & $\begin{array}{l}0,37 \\
0,021\end{array}$ & $\begin{array}{l}1,13 \\
0,311\end{array}$ & $\begin{array}{l}0,0034 \quad \pm \\
0,00001\end{array}$ \\
\hline & Conilon & $\begin{array}{l}5,76 \\
0,011\end{array}$ & $\begin{array}{l}1,16 \\
0,015\end{array}$ & $\begin{array}{l}0,40 \\
0,059\end{array}$ & $\begin{array}{l}0,69 \\
0,025\end{array}$ & $\begin{array}{l}0,0041 \quad \pm \\
0,00002\end{array}$ \\
\hline \multirow[t]{2}{*}{$\begin{array}{l}\text { Prensa } \\
\text { Francesa }\end{array}$} & Arábica & $\begin{array}{l}5,03 \\
0,000\end{array}$ & $\begin{array}{l}2,71 \\
0,017\end{array}$ & $\begin{array}{l}1,59 \\
0,004\end{array}$ & $\begin{array}{l}1,91 \\
0,387\end{array}$ & $\begin{array}{l}0,0096 \quad \pm \\
0,00002\end{array}$ \\
\hline & Conilon & $\begin{array}{l}5,70 \\
0,083\end{array}$ & $\begin{array}{l}1,79 \\
0,142\end{array}$ & $\begin{array}{l}1,85 \\
0,019\end{array}$ & $\begin{array}{l}1,39 \\
0,683\end{array}$ & $\begin{array}{l}0,0135 \quad \pm \\
0,00005\end{array}$ \\
\hline
\end{tabular}

Fonte: Os autores.

Entende-se que a acidez no café tem influência direta sobre o sabor e aroma da bebida. Ela é determinada pela concentração do íon de hidrogênio $(\mathrm{pH})$. Por isso, as amostras de infusão dos cafés preparadas com os grãos de café conilon torrados e nas moagens especificas, por todos os métodos de preparo da bebida avaliados neste trabalho, 
conferiram valores de $\mathrm{pH}$ maiores do que nas mesmas amostras de cafés preparados com os grãos de café arábica. Segundo os estudos de Sivetz e Desrosier (1979), ocorrem diversas variações no $\mathrm{pH}$ no momento da torra, e estas variações podem ser de muita importância na aceitação do produto pelo consumidor, e os mesmos sugerem que o pH ideal deve estar entre 4,95 a 5,20, sem excesso de amargor ou acidez.

Na tabela 1, é possível perceber que para todas as amostras de todos os métodos de preparo de café, o pH daquelas que foram utilizados o café torrado e moído conilon apresentaram maiores em relação aos aqueles com pó arábica e de modo inverso, menores valores de acidez. Com destaque para amostra preparada pelo método turco, do café conilon que apresentou maior $\mathrm{pH}$ de todas as amostras $(5,89)$, consequentemente também mostrou-se a amostra de menor acidez $(0,90 \%)$. Em algumas amostras nota-se que o $\mathrm{pH}$ encontra-se acima da faixa sugerida como ideal $(4,95$ a 5,20), todavia, seria preocupante se estes valores estivem abaixo desta faixa, o que poderia favorecer excesso de amargor ou acidez a bebida.

Os lipídios possuem um efeito benéfico na qualidade da bebida do café, pois, durante a torrefação, eles concentram-se nas áreas externas, formando na semente uma camada protetora contra eventuais perdas ocasionadas pelo processo (PIMENTA, 2003). Em relação ao conteúdo de lipídios, os métodos de preparo da bebida tiveram uma variação, ou seja, em alguns métodos preparados (Turco, Gelado e Francesa) com café arábica o teor de lipídeos foi maior e nos outros métodos preparados (Expresso, Italiano, Tradicional e Hario V60) com o conilon o teor de lipídeos foi maior. Esse comportamento não está de acordo com os resultados obtidos por MAZZAFERA et al. (1998), onde foi avaliado os grãos de café, e o café arábica apresentou um teor maior do que o café conilon. Para melhores resultados estas análises referentes a teor de lipídeos poderiam ter sido refeitas.

Com a avaliação de resíduos seco nas amostras investigadas neste estudo, as amostras provenientes da extração pelo método italiano e turco preparados com os grãos conilon foram as que apresentaram maiores valores de resíduo seco, 4,90\% e 4,37\%, respectivamente, e o menor teor deste parâmetro, para o café gelado $(0,40 \%)$, deste mesmo tipo de grão. Todas as amostras preparadas com o café conilon em todos os diferentes métodos de preparação avaliados, apresentaram-se com valores superiores em relação as amostras de café preparados com grãos arábica, com exceção do método expresso que apresentou valores iguais $(1,44 \%)$ tanto na amostra feita com café conilon, quanto para com o arábica.

O conteúdo de cafeína obtido nas amostras apresentou valores de cafeína sempre maiores nas amostras preparadas com grãos do café conilon, comparada com as amostras de café com grãos arábica, este resultado está de acordo com os estudos de Illy e Vianni (1996) que classificam os cafés robustos (conilon), como bebida neutra, com maiores teores de cafeína e compostos fenólicos, e os cafés arábica, com concentrações maiores de lipídeos. Sendo a amostra preparada pelo método turco com essa espécie de café (conilon) a que apresentou maior conteúdo de cafeína na amostra (0,0149 \pm 0,000038), isso pode ser explicado pelo fato, da ausência de um sistema de filtração no momento do preparo da bebida por esse método. E a amostra desta mesma espécie que apresentou menor conteúdo de cafeína foi pelo método de café Cold Brew (gelado) $(0,0041 \pm 0,000020)$, isto já era esperado, visto que, o Cold Brew é um café de extração 
a frio $\left(10{ }^{\circ} \mathrm{C}\right)$ e o poder de extração de cafeína a frio é menor do que a quente, mesmo levando em consideração o tempo de 24 horas de extração.

\section{CONSIDERAÇÕES FINAIS (ou Conclusão)}

A partir do presente estudo, foi possível a realização da caracterização físico-químicas de infusões de café obtidos a partir dos principais métodos de preparo de café, sendo estes métodos, o expresso, filtro tradicional, filtro Hario V60, italiano, turco e Cold Brew (gelado), estas infusões deste estudo foram provenientes de duas variedades de grão de café, o arábica e conilon. Essas características investigadas estão diretamente relacionadas a propriedades que conferem a qualidade da bebida (o café). Com o estudo, foi constatado que as amostras de café preparadas com o grão conilon em todos os métodos de preparo da bebida apresentaram resultados maiores em relação as amostras preparadas com o grão arábica nos parâmetros de $\mathrm{pH}$, resíduo seco e cafeína. E maiores teores de acidez para as amostras preparadas com grão arábica. Em relação ao conteúdo de lipídios, os métodos de preparo da bebida não apresentaram uma linearidade nos resultados, de modo que, em alguns métodos preparados (Turco, Gelado e Francesa) com café arábica o teor de lipídeos foi maior e nos outros métodos preparados (Expresso, Italiano, Tradicional e Hario V60) com o conilon o teor de lipídeos foi maior.

\section{REFERÊNCIAS}

CORTES, F.F. Nota sobre um novo processo de doseamento de cafeína no café. Rev. Soc. Bras. Quim. v. 4, p. 105, 1933.

ILLY, A.; VIANNI, R. Espresso coffee: the chemistry of quality. San Diego: Academic, 1996. p. 253.

INSTITUTO ADOFLO LUTZ. Normas Analíticas do Instituto Adolfo Lutz. v. 1: Métodos Químicos e Físicos para Análise de Alimentos. São Paulo: IMESP. 3.ed 1985. MARTINEZ, H. E. P.; POLTRONIERI, Y.; FARAH, A.; PERRONE, D. Zinc supplementation, production and quality of coffee beans. RevistaCeres, v.60, n.2, 2013. MATUlOVÁ, M. CAPEK, P. KANEKO, S. NAVARINI, L. LIVERANIT, F. S. Structure of arabinogalactan oligosaccharides derived from arabinogalactan-protein of Coffea arabica instant coffee powder. Carbohydrate Research, Amsterdam, v. 346, n. 8 , p. 1029-1036, 2011.

MAZZAFERA, P.; SOAVE, D.; ZULO, M.A.T.; GUERREIRO FILHO, O. Oil content of green beans from some species. Bragantia, v.57, n.1, p. 45-48, 1998.

MOURA, S. C. S. R. GERMER, S. P. M.; ANJOS, V. D. de A.; MORI, E. E. M.; MATTOSO, L. H. C.; FIRMINO, A.; NASCIMENTO, C. J. F. Avaliação física, química e sensoriais de blends de café arábica com café Canephora (robusta). Brazilian Journal of Food Technology, Campinas, v. 10, n. 4, p. 271-277, 2007a.

NUNES, A. M. Validação de Métodos Analíticos, Laboratório de Metrologia Química. Pelotas, 2010. p. 9-21.

PEREIRA, R. G. F. A. Efeito da inclusão de grãos defeituosos na composição química e qualidade do café (Coffea arábica L.) "estritamente mole". 1997. 96 f. Tese (Doutorado) - Universidade Federal de Lavras, Lavras, 1997.

PIMENTA, C. J. Época de colheita e tempo de permanência dos frutos à espera da secagem, na qualidade do café. 2001. 145 f. Tese (Doutorado em Química, FísicoQuímica e Bioquímica de Alimentos) - Universidade Federal de Lavras, Lavras, 2001. PIMENTA, C.J. Qualidade do café. Lavras: Ed. da Ufla, 2003. 304p. 